Original Article

\title{
The effect of virtual reality-based eccentric training on lower extremity muscle activation and balance in stroke patients
}

\author{
Seung Kyu Park, PhD, PT ${ }^{1)}$, Dae Jung Yang, PhD, PT ${ }^{1)}$, Yo Han Uhm, PT ${ }^{1)}$, \\ JAE Won Heo, $\mathrm{PT}^{1)}$, JE Ho KIM, PhD, $\mathrm{PT}^{1)^{*}}$ \\ 1) Department of Physical Therapy, Graduate School of Physical Therapy, Sehan University: \\ 1113 Noksaek-ro, Samho-eup, Yeongam-gun, Jeollanam-do, Republic of Korea
}

\begin{abstract}
Purpose] The purpose of this study was to examine the effect of virtual reality-based eccentric training on lower extremity muscle activity and balance in stroke patients. [Subjects and Methods] Thirty stroke patients participated, with 15 patients allotted to each of two eccentric training groups: one using a slow velocity (group I) and one using a fast velocity (group II). The virtual reality-based eccentric training was performed by the patients for 30 minutes once a day, 5 days a week, for 8 weeks using an Eccentron system. Surface electromyography was used to measure the lower extremity muscle activity, while a BioRescue was used to measure balancing ability. [Results] A significant difference in lower extremity muscle activation and balance ability was observed in group I compared with group II. [Conclusion] This study showed that virtual reality-based eccentric training using a slow velocity is effective for improving lower extremity muscle activity and balance in stroke patients.

Key words: Eccentric training, Muscle activation, Balance
\end{abstract}

(This article was submitted Feb. 4, 2016, and was accepted Apr. 7, 2016)

\section{INTRODUCTION}

Stroke refers to damage of the central nervous system caused by infarction and hemorrhage. It includes neurological disorders lasting for longer than 24 hours, and the major symptoms of stroke are sensory loss, motor weakness and loss of balance ${ }^{1)}$. Most stroke patients show muscle weakening because of changes in the muscle fiber features and a decrease in excitability of the cerebral cortex. Weakening of lower extremity muscles has a significant correlation with balance and walking ability, leading to the conclusion that muscle strength training is necessary to improve the balancing ability of stroke patients $^{2-4)}$.

Eccentric training, among other training methods for muscle strengthening, uses muscle contractions that involve lengthening. It stimulates the growth and production of muscle cells by stimulating collagen synthesis in the muscle and tendon system $^{5)}$. Eccentric strength is more preserved than concentric strength following stroke ${ }^{6}$, suggesting that training with eccentric contractions may provide a more intense training stimulus. Furthermore, evidence from healthy adults suggests that supraspinal motor systems are engaged differently by eccentric contractions when compared with concentric contractions ${ }^{7)}$. In addition, velocity affects muscle strengthening training. Type II fiber is more dependent on the velocity compared with type I fiber ${ }^{8)}$. While training with a low velocity increases coherence of myosin, training with a high velocity increases muscle strength by increasing the cross-sectional size of muscles ${ }^{9}$. There are difficulties presented regarding improvements on motor control due to a lack of feedback and a decrease in motivation of the target in muscular strength training. However, there is an implied need for training based on virtual reality to complement this ${ }^{10,11)}$.

Training based on virtual reality is used in the rehabilitation training processes of various diseases such as skeletal and

*Corresponding author. Je Ho Kim (E-mail: albam20@naver.com)

(C2016 The Society of Physical Therapy Science. Published by IPEC Inc.

This is an open-access article distributed under the terms of the Creative Commons Attribution Non-Commercial No Derivatives (by-nc-nd) License $<$ http://creativecommons.org/licenses/by-nc-nd/4.0/>. 
muscular system diseases and nervous system diseases to provide feedback about the characteristics of movements from situations similar to an actual environment and is an effective way to improve functional performance ${ }^{12,13)}$.

Studies on virtual reality are being actively conducted, but there is still a lack of studies that combines it with eccentric training as well as studies that compared the training effect by velocity. Therefore, the purpose of this study was to analyze the effect of a virtual reality-based eccentric training intervention on lower extremity muscle activation and balance in stroke patients and subsequently use it as basic data for the rehabilitation training of stroke patients.

\section{SUBJECTS AND METHODS}

This study was approved by bioethics Committee of Sehan university center (IRB) (Approval number: 2014-06) on July 11, 2014.This study selected 30 patients who satisfied detailed selection standards targeting patients hospitalized after the diagnosis of hemiplegia because of stroke. The detailed selection standards included diagnosis of stroke within the past year, the ability to communicate as indicated by achieving higher than 24 points on the Korean mini-mental status examination, the ability to walk more than $10 \mathrm{~m}$ independently, and the lack of any skeletal or muscular diseases that could affect the experiment. The subjects of this study were randomly allotted to either a virtual reality-based eccentric training using a slow velocity group (group I), or a virtual reality-based eccentric training using a fast velocity group (group II). General physical therapy was conducted including developmental therapy for the central nervous system before virtual reality-based eccentric training. For virtual reality-based eccentric training, an Eccentron (BTE Technologies Inc., Hanover, MD, USA) was used ${ }^{14)}$, this system is comprised of a screen used to narrate the virtual reality and provide feedback during training and an ergometer with a force plate. With this system, training is performed under closed kinematic chain conditions, and when negative work is performed at a velocity of 1-35 rpm, it causes eccentric contraction in the hip joint, knee joint, and ankle joint. Velocity is categorized as follows: slow velocity, 1-12 rpm, medium velocity, 13-24 rpm, high velocity, 25-35 rpm. The training was performed for 30 minutes a day, five times a week for 8 weeks.

An MP100 surface electromyography (EMG) system (Biopac Systems Inc., Goleta, CA, USA) was used to measure the lower extremity muscle activation. It was attached to the vastus lateralis, vastus medialis, and gastrocnemius muscles by bipolar electrode in parallel with the direction of muscle fibers on each muscle belly. The percentage of reference voluntary contraction (\%RVC) was used to standardize the muscle activation. The Sampling rate was set 1,024 Hz, and notch filter and band pass filter were set $60 \mathrm{~Hz}$ and $30-450 \mathrm{~Hz}$, respectively, and the collected signal was processed with RMS. During maintaining 5 seconds a low squatting position, after it was measured muscle activation of measuring muscle, RVC value was calculated with analyzing signals with 3 seconds excluding first 1 second and last 1 second and also \%RVC value was do with comparing muscle activation value measured during LOS test. The mean values of 3 measurements were used as the muscle activation data.

A BioRescue (RM Ingenierie, Rodez, France), which can measure the moving distance and area of the center of pressure (COP), was used to measure balance ability ${ }^{15}$. This study measured the limit of stability (LOS), which is the furthest distance weight can be shifted in any direction without loss of balance.

The PASW Statistics for Windows, Ver. 18.0, statistical software was used for analysis of the results of this study. Descriptive statistics were used for the characteristics the subjects, and analysis of covariance (ACOVA) was conducted to examine the differences in lower extremity muscle activation and balance ability before and after the intervention between groups. The Statistical significance level was $\alpha=0.05$.

\section{RESULTS}

Table 1 summarizes the data concerning the general characteristics of the subjects. Table 2 summarizes the differences in lower extremity muscle activation and balance ability before and after the intervention for Group I and Group II. Group I showed statistically significant differences in LOS and gastrocnemius muscle activation $(\mathrm{p}<0.05)$, and in vastus lateralis and vastus medialis muscle activation $(\mathrm{p}<0.01)$ compared with Group II before and after the intervention.

\section{DISCUSSION}

In aiming to identify the efficient velocity for improvements of lower extremity muscle activation and balance ability as well as to confirm the effect of virtual reality-based eccentric training on lower extremity muscle activation and balance in stroke patients, this study confirmed that virtual reality-based eccentric training using a slow velocity resulted in significant improvements in lower extremity muscle activation and balance ability. LaStayo et al. ${ }^{16)}$ divided 21 elderly participants who had experienced falls into an eccentric resistant exercise group and the traditional muscular strength exercise group and subjects them to their respective interventions for 11 weeks. Their results showed a significant increase in BBS scores and changes in posture when comparing the eccentric resistant exercise group with the traditional muscular strength training group. Jegu et al. ${ }^{17)}$ divided 80 patients with kneecap arthritis into an eccentric training groups and concentric training groups subjects them to their respective interventions for 6 weeks. The results revealed a significant decrease in changes in posture 
Table 1. General characteristics of the subjects

\begin{tabular}{lcc}
\hline & $\begin{array}{c}\text { Group I } \\
(\mathrm{n}=15)\end{array}$ & $\begin{array}{c}\text { Group II } \\
(\mathrm{n}=15)\end{array}$ \\
\hline Gender (male/female) & $8 / 7$ & $8 / 7$ \\
Age (years) & $61.0 \pm 4.2$ & $60.9 \pm 4.2$ \\
Weight $(\mathrm{kg})$ & $66.9 \pm 5.2$ & $65.9 \pm 7.3$ \\
Height $(\mathrm{cm})$ & $167.3 \pm 6.2$ & $168.0 \pm 4.2$ \\
Stroke duration (months) & $5.4 \pm 1.4$ & $5.3 \pm 1.2$ \\
\hline
\end{tabular}

Values are shown as the mean $\pm \mathrm{SD}$.

Group I: isokinetic eccentric training + slow velocity (IET+SV).

Group II: isokinetic eccentric training + fast velocity (IET+FV).

Table 2. Comparison of lower extremity muscle activation and balance ability between groups

\begin{tabular}{lcccc}
\hline & \multicolumn{2}{c}{ Group I $(\mathrm{n}=15)$} & \multicolumn{2}{c}{ Group II $(\mathrm{n}=15)$} \\
\cline { 2 - 5 } & Pre & Post & Pre & Post \\
\hline VL (\%) & $31.9 \pm 2.5$ & $39.9 \pm 3.5^{* *}$ & $31.4 \pm 3.6$ & $37.4 \pm 3.5$ \\
VM (\%) & $29.5 \pm 3.9$ & $37.5 \pm 5.0^{* *}$ & $29.8 \pm 4.7$ & $35.8 \pm 4.6$ \\
GCM $(\%)$ & $27.2 \pm 4.7$ & $35.2 \pm 5.3^{*}$ & $27.0 \pm 5.7$ & $33.1 \pm 4.7$ \\
LOS $\left(\mathrm{cm}^{2}\right)$ & $90.5 \pm 9.2$ & $168.8 \pm 9.1^{*}$ & $91.2 \pm 9.0$ & $147.6 \pm 7.2$ \\
\hline
\end{tabular}

Values are shown as the mean $\pm \mathrm{SD}$.

*significant difference between the two groups $(\mathrm{p}<0.05)$.

**significant difference between the two groups $(\mathrm{p}<0.01)$.

Group I: isokinetic eccentric training + slow velocity (IET+SV).

Group II: isokinetic eccentric training + fast velocity (IET+FV).

VL: vastus lateralis; VM: vastus medialis; GCM: gastrocnemius; LOS: limited of stability

tests in comparing of the eccentric training group with the concentric training group. Tsakils et al. ${ }^{18)}$ showed significant decreases in both moving area and speed, focusing on body's center of pressure, in stroke patients after 4 weeks of balance training based on virtual reality. Groups I and II, which were subjected to 8-week interventions with eccentric training based on virtual reality in this study, also showed an increase in their limits of stability, improving their balance ability. Usually, eccentric shrinkage is activated to control and maintain posture stability ${ }^{19}$ ), and since training based on virtual reality is provided with real-time feedback information and it motivates subjects ${ }^{20,21)}$, it can be deduced that eccentric training based on virtual reality increases balance ability.

In an intervention conducted for 6 weeks for 14 stroke patients divided into a muscular strength training groups using a slow velocity and a muscular strength training groups using a significant fast velocity, Cha et al. ${ }^{22)}$ showed a significant decrease in the dynamic balance test in the training groups. Their study also showed a significant difference in the LOS between virtual reality-based eccentric training using a slow velocity and virtual reality-based eccentric training using a fast velocity. Since the balancing ability of stroke patients shows a high correlation with the muscle strength of the lower extremity and a fast velocity, muscular strength training of legs leads to a reduction in muscle shrinkage, reducing the crossbridge of actin and myosin because it causes overload in the tissue ${ }^{23)}$. It is thought that eccentric training using a slow velocity that causes co-contraction of type I fiber and type II fiber results in a significant difference in improvements of balance ability by increasing the muscle strength of the lower extremity.

This study confirmed that virtual reality-based eccentric training using a slow velocity is effective for improving lower extremity muscle activation and balance ability in stroke patients. The limitation of this research is that it is difficult to the findings to generalize all stroke patients due to the small number of subjects. Therefore, additional study regarding the effects of virtual reality-based eccentric training on cardiopulmonary function and the quality of life in stroke patients is necessary.

\section{ACKNOWLEDGEMENT}

This research was supported by a research grant of Sehan University in 2016. 


\section{REFERENCES}

1) Shin SH, Yu JH, Jung JH, et al.: Effects of dual-task performance on postural sway of stroke patients with experience of fall. J Phys Ther Sci, 2012, 24: 975-978. [CrossRef]

2) Snow LM, Low WC, Thompson LV: Skeletal muscle plasticity after hemorrhagic stroke in rats: influence of spontaneous physical activity. Am J Phys Med Rehabil, 2012, 91: 965-976. [Medline] [CrossRef]

3) Lee KB, Kim JH, Lee KS: The relationship between motor recovery and gait velocity during dual tasks in patients with chronic stroke. J Phys Ther Sci, 2015, 27: 1173-1176. [Medline] [CrossRef]

4) Bovonsunthonchai S, Hiengkaew V, Vachalathiti R, et al.: Gait symmetrical indexes and their relationships to muscle tone, lower extremity function, and postural balance in mild to moderate stroke. J Med Assoc Thai, 2011, 94: 476-484. [Medline]

5) Guilhem G, Guevel A: Neuromuscular and muscle tendon system adaptations to isotonic and isokinetic eccentric exercise. Ann Phys Rehabil Med, 2010, 53: 319-341. [Medline] [CrossRef]

6) Eng JJ, Lomaglio MJ, Macintyre DL: Muscle torque preservation and physical activity in individuals with stroke. Med Sci Sports Exerc, 2009, 41: 1353-1360. [Medline] [CrossRef]

7) Fang Y, Siemionow V, Sahgal V, et al.: Greater movement-related cortical potential during human eccentric versus concentric muscle contractions. J Neurophysiol, 2001, 86: 1764-1772. [Medline]

8) Valour D, Rouji M, Pousson M: Effects of eccentric training on torque-angular velocity-power characteristics of elbow flexor muscles in older women. Exp Gerontol, 2004, 39: 359-368. [Medline] [CrossRef]

9) Shepstone TN, Tang JE, Dallaire S, et al.: Short-term high- vs. low-velocity isokinetic lengthening training results in greater hypertrophy of the elbow flexors in young men. J Appl Physiol 1985, 2005, 98: 1768-1776. [Medline] [CrossRef]

10) Lee KH: Effects of a virtual reality-based exercise program on functional recovery in stroke patients: part 1. J Phys Ther Sci, 2015, 27: 1637-1640. [Medline] [CrossRef]

11) Laver K, George S, Thomas S, et al.: Virtual reality for stroke rehabilitation: an abridged version of a Cochrane review. Eur J Phys Rehabil Med, 2015, 51: 497-506. [Medline]

12) Corbetta D, Imeri F, Gatti R: Rehabilitation that incorporates virtual reality is more effective than standard rehabilitation for improving walking speed, balance and mobility after stroke: a systematic review. J Physiother, 2015, 61: 117-124. [Medline] [CrossRef]

13) Yom C, Cho HY, Lee B: Effects of virtual reality-based ankle exercise on the dynamic balance, muscle tone, and gait of stroke patients. J Phys Ther Sci, 2015, 27: 845-849. [Medline] [CrossRef]

14) Gerber JP, Marcus RL, Leland ED, et al.: The use of eccentrically biased resistance exercise to mitigate muscle impairments following anterior cruciate ligament reconstruction: a short review. Sports Health, 2009, 1: 31-38. [Medline] [CrossRef]

15) Baek IH, Kim BJ: The effects of horse riding simulation training on stroke patients' balance ability and abdominal muscle thickness changes. J Phys Ther Sci, 2014, 26: 1293-1296. [Medline] [CrossRef]

16) LaStayo PC, Ewy GA, Pierotti DD, et al.: The positive effects of negative work: increased muscle strength and decreased fall risk in a frail elderly population. J Gerontol A Biol Sci Med Sci, 2003, 58: M419-M424. [Medline] [CrossRef]

17) Jegu AG, Pereira B, Andant N, et al.: Effect of eccentric isokinetic strengthening in the rehabilitation of patients with knee osteoarthritis: Isogo, a randomized trial. Trials, 2014, 15: 106. [Medline] [CrossRef]

18) Tsaklis PV, Grooten WJ, Franzén E: Effects of weight-shift training on balance control and weight distribution in chronic stroke: a pilot study. Top Stroke Rehabil, 2012, 19: 23-31. [Medline] [CrossRef]

19) Booysen MJ, Gradidge PJ, Watson E: The relationships of eccentric strength and power with dynamic balance in male footballers. J Sports Sci, 2015, 33: 2157-2165. [Medline] [CrossRef]

20) Anderson KR, Woodbury ML, Phillips K, et al.: Virtual reality video games to promote movement recovery in stroke rehabilitation: a guide for clinicians. Arch Phys Med Rehabil, 2015, 96: 973-976. [Medline] [CrossRef]

21) Mao Y, Chen P, Li L, et al.: Virtual reality training improves balance function. Neural Regen Res, 2014, 9: 1628-1634. [Medline] [CrossRef]

22) Cha EJ, Oh JK, Yoon JH: Effect of isokinetic exercise on strength of knee muscle, balance and gait ability in the hemiplegic stroke patients. Kor J Spots Sci, 2013, 22: 1173-1183.

23) Guilhem G, Guével A, Cornu C: A standardization method to compare isotonic vs. isokinetic eccentric exercises. J Electromyogr Kinesiol, 2010, 20: 10001006. [Medline] [CrossRef] 